\title{
Personality types of women attending an STD clinic: correlation with keeping first review appointments
}

\author{
D HAMMOND, * R D MAW, $\dagger$ M MULHOLLAND $\dagger$ \\ From the *Department of Psychology, University of Ulster, Belfast, and the $\dagger$ Department of Genitourinary \\ Medicine, Royal Victoria Hospital, Northern Ireland
}

SUMMARY One hundred and eighty new women patients attending a sexually transmitted disease (STD) clinic answered the Eysenck personality questionnaire (EPQ) ${ }^{1}$ which measures psychoticism, extraversion, neuroticism, and a tendency to "fake good". These personality scores were correlated with the patients' attendance or non-attendance for their first review appointments. The results showed that the mean psychoticism scale scores of the 41 non-attenders was significantly higher than that of the 139 who kept their first appointment. This relation was confirmed using point biserial correlations. The mean scores of non-attenders on the other three EPQ scales were not significantly different from those of attenders, and none of the correlations between the other EPQ scales and this behavioural criterion was significant. The psychoticism scale is tentatively recommended for identifying women patients who may need special counselling about the importance of keeping their first review appointment.

An important school of thought in psychology assumes that all behavioural differences reflect personality differences. ${ }^{2}$ This paper reports the results of a study designed to examine the relation between the personalities of new women patients attending a sexually transmitted disease (STD) clinic and their non-attendance or attendance for their first review appointment.

The Eysenck personality questionnaire (EPQ) was used to assess personality for the following reasons. Firstly, it is a comprehensive measure of the three main personality dimensions described by Eysenck. These are (1) psychoticism, which could be termed tough mindedness (traits shown are solitariness, troublesomeness, cruelty, unfeelingness and insensitivity, hostility and aggression, and predisposition to psychotic psychiatric illness, psychopathic personality disorder, drug or alcohol addiction, or criminality); (2) extraversion (extraverted people are sociable, impulsive, lively, and lacking social inhibition); and (3) neuroticism, which refers to emotionality (traits include strong but labile and conflicting emotions, anxiety, being easily upset, and having a predisposi-

\footnotetext{
Address for reprints: Dr R D Maw, Department of Genitourinary Medicine, Royal Victoria Hospital, Grosvenor Road, Belfast BT12 6BA, Northern Ireland
}

Accepted for publication 16 January 1989 tion to neurotic psychiatric illness). The EPQ was also designed to detect the tendency to "fake good", that is, to give answers that are perceived as being socially acceptable rather than true, and as being orthodox, conventional, and law abiding. Secondly, the EPQ was used because independent research has confirmed the satisfactoriness of its psychometric characteristics. ${ }^{4}$ Thirdly, it is easy to administer and score and can be answered in about 15 minutes only, which would be essential if such a questionnaire were to be useful in a busy STD clinic.

Attendance for follow up after the first visit to an STD clinic is of great importance for (a) assessing the success of any initial treatment that may have been given, (b) assessing the success of tracing sexual contacts, and (c) giving results of tests that had been carried out. The last is of particular importance for women as the diagnosis of gonorrhoea often depends on culture results and the diagnosis of infection with Chlamydia trachomatis depends on laboratory testing. These two conditions are the commonest causes of pelvic inflammatory disease in young women in the Western world, ${ }^{5}$ and it is therefore essential to make accurate diagnoses and be able to give adequate treatment. Results of cervical cytology are available only at follow up, which is of particular importance to women who attend STD clinics, who have a high incidence of abnormal results to this test, ${ }^{6}$ and especially to those who have genital warts or who have 
been in contact with genital warts. ${ }^{7}$ Failure to attend for follow up therefore has obvious implications in treating patients successfully and preventing the spread of infection in the community.

Examination of records at the Royal Victoria Hospital, Belfast, showed that about $25 \%$ of women failed to keep their first follow up visit. No assessment technique has been devised for identifying women patients at STD clinics likely to be non-attenders. The lack of reports published on this subject indicates a general neglect of this important issue by researchers. This oversight is increasingly important in view of the increased incidence of STD in the community. If an accurate predictor of non-attendance were developed, it would help identify those in need of special counselling to persuade them to keep their first follow up appointment.

\section{Methods}

We gave 180 consecutive new women patients attending the STD clinic of the Royal Victoria Hospital, Belfast, written information explaining the nature of the study. We asked them to complete the questionnaire before any consultation with the doctor had taken place. They were assured that answers would be treated as confidential and the results not entered in their clinic chart. All took part in the study voluntarily.

The EPQ has 90 questions, each requiring a "yes" or "no" answer, of which 25 assess psychoticism, 21 extraversion, 23 neuroticism, and 21 the tendency to "fake good". The last group of questions is called the lie scale, whereas the other three groups are named after the personality dimensions they purport to gauge. Statistical analyses used were $t$ tests for independent samples and point biserial correlations.

\section{Results}

The mean (SD) age of the 180 patients was $25 \cdot 3(7 \cdot 3)$. Table 1 shows the mean (SD) scores of attenders and non-attenders. From this it can be seen that, compared with the attenders, the non-attenders had slightly higher mean scores on the four EPQ scales and slightly higher standard deviations on all these scales, except for the neuroticism scale on which their standard deviation was slightly lower.

Table 1 Mean (SD) scores in the four scales of the Eysenck personality questionnaire (EPQ) completed by 180 new women patients related to their attendance for the first follow up appointment

\begin{tabular}{lcc}
\hline & \multicolumn{2}{l}{ Follow up appointment } \\
\cline { 2 - 3 } EPQ scales & $\begin{array}{l}\text { Attenders } \\
(n=139)\end{array}$ & $\begin{array}{l}\text { Non-attenders } \\
(n=41)\end{array}$ \\
\hline Psychoticism & $2 \cdot 42(2 \cdot 19)$ & $3 \cdot 37(2 \cdot 51)$ \\
Extraversion & $14 \cdot 15(4 \cdot 42)$ & $15 \cdot 32(4 \cdot 44)$ \\
Neuroticism & $13 \cdot 50(4 \cdot 78)$ & $15 \cdot 05(4 \cdot 51)$ \\
Lie & $8 \cdot 51(3.97)$ & $9 \cdot 51(4 \cdot 11)$ \\
\hline
\end{tabular}

Table 2 The Eysenck's norms of scores in the four scales of the Eysenck personality questionnaire (EPQ) answered by adult women from the general population

\begin{tabular}{llc}
\hline EPQ scales & $\begin{array}{l}\text { No of } \\
\text { women }\end{array}$ & Mean $(S D)$ scores \\
\hline Psychoticism & 3262 & $2 \cdot 63(2 \cdot 36)$ \\
Extraversion & 3262 & $12 \cdot 60(4 \cdot 83)$ \\
Neuroticism & 3262 & $12 \cdot 74(5 \cdot 20)$ \\
Lie & $2462 *$ & $7 \cdot 73(4 \cdot 18)$ \\
\hline
\end{tabular}

*Fewer women were tested on the lie scale than on the other three EPQ scales as some were tested with a version of the questionnaire not containing the lie scale. ${ }^{13}$

Table 2 gives an extract from the Eysencks' norms for adult women in the general population. ${ }^{8}$ Compared with the Eysencks' study population our nonattenders for follow up had a slightly higher mean psychoticism scale score, whereas the attenders had a slightly lower mean score on this scale. On each of the other three EPQ scales, non-attenders and attenders had a higher mean score than those of the Eysencks' population.

Table 3 is a summary of the results of $t$ tests for independent samples used to assess the significance of the differences between the means of our two groups of patients on the EPQ scales. Non-attenders had a significantly higher mean score than attenders on the psychoticism scale of the EPQ ( $p<0.05$ for a two tailed rejection region). No significant differences were seen, however, between their means on the other EPQ scales.

Table 4 gives the point biserial correlations between the 180 women's scores on the EPQ scales and their non-attendance or attendance. These correlational analyses were performed to examine further the relation between the EPQ scales and this behavioural criterion. Significant modest positive correlation was seen between these patients' psychoticism scale scores and their non-attendance or attendance at the STD clinic ( $p<0.05$ on a two tailed test). None of the correlations between the other three EPQ scales and this behavioural criterion was significant. From these results we concluded that there was a small significant relation between the psychoticism scale only and nonattendance or attendance for follow up at the clinic. This relation was examined further in an expectancy chart ${ }^{9}$ presented in table 5. This chart shows the percentage of non-attenders in each of three psychoti-

Table 3 Summary of the results of $t$ tests for independent samples used to assess the significance of the differences between the means on the EPQ scales obtained by 41 nonattenders and 139 attenders for their first follow up appointment at the STD clinic

\begin{tabular}{llll}
\hline EPQ scales & $t$ value & $\begin{array}{l}\text { Degrees of } \\
\text { freedom }\end{array}$ & $\begin{array}{l}\text { Probability for } \\
\text { two tailed } \\
\text { rejection region }\end{array}$ \\
\hline Psychoticism & 2.08 & 178 & $<0.05$ \\
Extraversion & 1.48 & 178 & $>0.05$ \\
Neuroticism & 1.85 & 178 & $>0.05$ \\
Lie & 1.41 & 178 & $>0.05$ \\
\hline
\end{tabular}


Table 4 Point biserial correlations between the 180 female patients' scores on the EPQ scales and their non-attendance, or attendance, for their first follow up appointment at the STD clinic

\begin{tabular}{llll}
\hline & $\begin{array}{l}\text { Non- } \\
\text { attendance or } \\
\text { attendance }\end{array}$ & $\begin{array}{l}\text { Degrees of } \\
\text { freedom }\end{array}$ & $\begin{array}{l}\text { Probability for } \\
\text { two tailed } \\
\text { test of } \\
\text { significance }\end{array}$ \\
\hline Psychoticism & 0.17 & 178 & $<0.05$ \\
Extraversion & 0.11 & 178 & $>0.05$ \\
Neuroticism & 0.14 & 178 & $>0.05$ \\
Lie & 0.11 & 178 & $>0.05$ \\
\hline
\end{tabular}

cism scale score bands, each of which contained about one third of all the women patients. Higher psychoticism scale scores evidently tended to be associated with higher levels of non-attendance.

\section{Discussion}

This study indicates that there was a relation between personality, as measured by the EPQ, and women patients' failure to attend for the first follow up appointment at the STD clinic. Specifically, nonattenders were found to have a significantly higher mean score on the psychoticism scale than attenders. There was also a significant, but low, positive correlation between the patients' psychoticism scale scores and their non-attendance, or attendance, at the STD clinic. The mean scores of non-attenders on the other three EPQ scales, however, were not significantly different from those of attenders, and none of the correlations between the other EPQ scales and this behavioural criterion was significant.

Our findings suggest that patients with high scores on the psychoticism scale were not as fearful as those with low scores regarding possible damage to their health if they failed to keep their follow up appointment. This interpretation is consistent with the Eysencks' description of high scorers as having "a disregard for danger". ${ }^{10}$ The results also suggest that patients with high scores may not have been as concerned as low scorers to assist in contact tracing, which would accord with the Eysencks' account of high scorers as "not caring for people". Failure to carry out adequate contact tracing will of course result in further spread of infection and increased morbidity associated with infection. In view of the importance of identifying women who are likely to be non-attenders, methods

Table 5 Expectancy chart showing the relation between the 180 female patients' scores on the psychoticism scale of the $E P Q$ and non-attendance for their first follow up appointment at the STD clinic

\begin{tabular}{llc}
\hline $\begin{array}{l}\text { Scores on the psychoticism } \\
\text { scale of the EPQ }\end{array}$ & $\begin{array}{l}\text { Total No } \\
\text { of patients }\end{array}$ & $\begin{array}{l}\text { No (\%) } \\
\text { non-attenders }\end{array}$ \\
\hline $0-1$ & 64 & $9(14)$ \\
$2-3$ & 66 & $15(23)$ \\
$4-25$ & 50 & $17(34)$ \\
\hline
\end{tabular}

should be devised to improve compliance. Goodrich found that counselling patients with gonorrhoea did improve compliance, ${ }^{11}$ but this does not take into account those whose diagnosis is made only when laboratory results become available. Nor does it take into account the possibility that special counselling may be necessary for certain groups of patients, such as those with a high psychoticism rating. Using the EPQ, Fulford et al did not find any significant association between the STD acquired and any of the personality scores, ${ }^{12}$ which may indicate that in people for whom a diagnosis has been made at the first visit, those who are less likely to attend for follow up should be identified. Although the relation between the psychoticism scale and non-attendance or attendance shown in this study is a weak one, it deserves further research. If this correlation were confirmed, an expectancy chart similar to that in table 5 could be used by staff to identify women likely to need special counselling to persuade them to keep their first follow up appointment. This would of course mean routinely asking all women newly attending the STD clinic to answer the questions on the psychoticism scale. Scoring the answers would place an extra burden on already overworked clinic staff, and the value of such a procedure therefore needs further assessment. A similar study has been carried out for men patients attending the same STD clinic, and we hope that the results from an expanded study population will be published soon.

\section{References}

1 Eysenck HJ, Eysenck SBG. Manual of the Eysenck personality questionnaire. London: Hodden \& Stoughton, 1975:5-16.

2 Kline P. Personality: measurement and theory. London: Hutchinson, 1983:65.

3 Eysenck HJ, Eysenck MW. Personality and individual differences. New York: Plenum Press, 1985:3-117.

4 Fonagy P, Higgitt A. Personality theory and clinical practice. London: Methuen, 1984:107.

5 Mårdh P-A. An overview of infectious agents of salpingitis, their biology and recent advances in methods of detection. Am J Obstet Gynecol 1980;138:933-51.

6 Maw RD, Hanley O. Cervical cytology figures for 1970-81. British Journal of Venereal Diseases 1983;59:408-9.

7 Campion MJ, Singer A, Clarkson PK, McCance DJ. Increased risk of cervical neoplasia in consorts of men with penile condylomata acuminata. Lancet 1985; i:943-8.

8 Eysenck HJ, Eysenck SBG. Manual of the Eysenck personality questionnaire. London: Hodden \& Stoughton, 1975:18.

9 McCormick EJ, Ilgen D. Industrial and organisational psychology. Eighth edition. New Jersey: Prentice-Hall 1985:126-7.

10 Eysenck HJ, Eysenck SBG. Manual of the Eysenck personality questionnaire. London: Hodden \& Stoughton, 1975:11.

11 Goodrich KK. Gonococcal infection: the effect of educational counselling on patient compliance. British Journal of Venereal Diseases 1981;57:137-40.

12 Fulford KWM, Catterall RD, Hoinville E, Lim KS, Wilson GD. Social and psychological factors in the distribution of STD in male clinic attenders. British Journal of Venereal Diseases 1983;59:381-5.

13 Eysenck HJ, Eysenck SBG. Manual of the Eysenck personality questionnaire. London: Hodder \& Stoughton, 1975:18. 